\title{
Ice Crystals Trajectory Calculations in a Turbofan Engine
}

\author{
Gilles Aouizerate, Virgile Charton, Morgan Balland \\ Safran Aircraft Engines, F-77550, Moissy-Cramayel, France \\ Jean-Mathieu Senoner, Pierre Trontin, Claire Laurent, Ghislain Blanchard and Philippe Villedieu \\ ONERA - The French Aerospace Lab, F-31055 Toulouse, France
}

This paper presents Ice Crystals particles trajectory simulations based on models representative of aircraft engines flying through realistic Ice Crystals clouds. The current study pursues of the work performed by Safran Aircraft Engines in the framework of the High Altitude Ice Crystals (HAIC) European research project. Results of the HAIC/High Ice Water Content (HIWC) projects flight campaigns are used to characterize the atmospheric environment in the Ice Crystals clouds. The present work benefits from the mixed-phased and glaciated particles trajectory modeling capabilities available in ONERA's icing numerical tools. Simulations are run on two distinct geometries: a generic engine Inlet $\&$ Fan, and a generic Fan \& Low Pressure Compressor. The first configuration allows the effects of centrifugation and fragmentation on particle concentrations at the engine's primary flow inlet. The influence of particle size is also studied. The second geometry provides qualitative information on preferential accretion sites within the engine. Simulation results obtained for this configuration are consistent with experimental observations of the so-called plateau effect.

\section{Nomenclature}

$\begin{array}{ll}\text { HAIC } & =\text { high altitude ice crystals } \\ H I W C & =\text { high ice water content } \\ I C I & =\text { ice crystals icing } \\ I W C & =\text { ice water content }\left(\mathrm{g} \cdot \mathrm{m}^{-3}\right) \\ L W C & =\text { liquid water content }\left(\mathrm{g} \cdot \mathrm{m}^{-3}\right) \\ M M D & =\text { mass median diameter }(\mathrm{m}) \\ P S D & =\text { particles size distribution } \\ T W C & =\text { total water content }\left(\mathrm{g} \cdot \mathrm{m}^{-3}\right)\end{array}$

II. Introduction

$\mathrm{T}$ HIS document presents part of the work performed by Safran Aircraft Engines in the framework of the High Altitude Ice Crystals (HAIC) European research project and beyond. The aim is to assess the new models implemented in CEDRE, ONERA's Multiphysics platform containing its 3D icing numerical suite, in terms of Ice Crystals particles trajectory simulation run in realistic conditions, that is: using real Ice Crystals cloud characterization data, on geometrical domains that are representative of a turbofan engine flying in conditions of Icing threat. However, the scope of this paper goes beyond simple tool assessment, since the influence of major parameters such as the Particles Size Distribution (PSD) or the flight phase is numerically studied.

This paper is organized as follows. Part III briefly describes the main capabilities of the CEDRE suite that are of interest for this study. Part IV presents the assumptions made to define the atmospheric conditions based on the interim results of the HAIC/HIWC flight campaigns and used to perform the numerical simulations. Part V deals with the calculations performed on a generic engine Inlet \& Fan and part VI on those run on an engine Fan \& Low Pressure Compressor. First, details on the computational domains and the mesh are provided. Then the simulated flight conditions are presented. Finally, the influence of several parameers is analyzed in detail. To prevent disclosure of intellectual property, the test cases on which those calculations have been performed are either adapted from geometry publicly available or simply designed especially for this study. The main findings of the present work are summarized in the conclusion. 


\section{CEDRE capabilities and limitations}

In the framework of the HAIC project, new models describing the behavior of Ice Crystals particles in an air flow (trajectory models) and their interactions with solid walls (impingement models and accretion models) were developed. Those models were implemented by ONERA and other project partners in their 2D tools and validated using academic test cases. ONERA implemented part of those models into CEDRE, its Multiphysics simulation platform containing its 3D multiphysics numerical tools suite. The trajectory models are directly extended to 3D, as well as most of the impingement models. As far as the accretion models are concerned however, the extension from 2 to 3 spatial dimension is not trivial and would require significant development and research efforts. For this reason CEDRE's capabilities in this domain remain limited. Nevertheless, an attempt to obtain a first order approximation of the location and severity of ice accretion is made in this paper.

Details regarding the Ice Crystal models developed within the HAIC project have already been described in detail elsewhere [1] [2] [3]. For this reason, these will not be presented in detail in the current work, but analyzed with respect to the additional capabilities resulting from their implementation in a 3D tool and their practical relevance for an engine manufacturer such as Safran Aicraft Engines.

\section{A. Particle trajectory capabilities}

Within the CEDRE suite, the Lagrangian solver SPARTE is devoted to the simulation of the particulate phase for both steady [4] and unsteady dispersed two-phase flows [5]. It is tracking each numerical particle individually along its path from its entrance into the domain to its exit. To determine the trajectory of each Ice Crystal particle SPARTE provides several drag models. In the framework of this study, the drag model proposed by Ganser [6] was adopted.

SPARTE does not only propose to describe the mechanical behavior of the particles. Melting and evaporation capabilities were also implemented into the solver. Those are based on work performed during the HAIC project [7].

\section{B. Impingement capabilities}

When an Ice Crystal particle hits a wall, SPARTE predicts three possible outcomes, or impact regimes:

- The particle may bounce. In that case an identical particle is reemitted in the flow by SPARTE with a modified velocity based on statistical models,

- The particle may fragment. In that case, a part of the particle (possibly empty) is re-emitted in the form of smaller particles whose velocity is also based on statistical models and another part of the particle (possibly empty) sticks to the wall (see the following bullet).

- Finally, the particle may entirely stick to the wall. In that case, the particle leaves the scope of the solver. The resulting ice or water remaining on the wall may either partially or totally accrete or runback. These phenomena are only partially approximated in this paper and would necessitate the use of another solver to be fully described numerically (see paragraph III.D).

The determination of the impact regime is based on interaction models detailed in [1] or [2]. Those models account for several physical parameters such as the kinetic energy of the incoming particles, their shape and size, their liquid fraction, their temperature and others. The constants present in these models were calibrated to match (among other) elementary crystal wall interaction experiments performed during the HAIC project [8] [9].

Note that so far, the impingement capabilities of SPARTE are limited to unheated walls.

\section{Additional capabilities}

CEDRE is a complete 3D multiphysics suite which includes several solvers [10]. The solvers relevant to icing applications are CHARME, a general purpose 3D Navier-Stokes solver which is able to deal with compressible reacting flows, SPIREE an Eulerian dispersed phase solver or FILM a wall liquid film (shallow water) and accretion (two-layer model) solver.

Calculations performed in this paper, rely on CHARME for the gas flow calculations and on SPARTE for the dispersed phase calculations. 
CEDRE has been extensively used at Safran Aircraft Engines. It is particularly suitable for turbomachinery calculations since it accurately deals with periodicities, mixing planes and moving walls.

\section{Accreted ice thickness approximation}

As stated earlier accretion models in CEDRE are still to be developed. However, using the ONERA 2D sticking efficiency models [1] [2], one can estimate at first approximation the location and the severity of ice accretion in the jet engine. Here after, the ice thickness calculation is detailed as well as hypothesis used.

In the first step, the local impinging Ice Crystal melting ratio $\eta$ is calculated:

$$
\eta=\left(1-Y_{s}\right)
$$

where $Y_{S}$ is the particle solid fraction and is a CEDRE output. The sticking efficiency $\varepsilon_{s}$, as defined and calibrated in ONERA 2D icing suite, is calculated with the following equation:

$$
\varepsilon_{s}=\left(K_{c}-2\right) \eta^{3}+\left(3-2 K_{c}\right) \eta^{2}+K_{c} \eta
$$

where $K_{c}=5 / 2$ [11]. It is then possible to obtain the ice deposit mass rate per unit area as follow:

$$
\dot{m}_{\text {dep }}=\varepsilon_{s} \dot{m}_{i m p}
$$

where $\dot{m}_{i m p}$, the impinging mass rate, is a CEDRE output. In the next step, the icing rate is calculated assuming that the totality of the sticking ice accounts for accretion, which is a very simple hypothesis (no evaporation or water runback). In addition, the ice layer erosion is not taken into account, as well as heat exchanges with the wall or the flow since the simulation is a one-step calculation:

$$
\dot{m}_{i c e}=\dot{m}_{d e p}
$$

Once we have the icing rate $\dot{m}_{i c e}$, the ice thickness can be deducted for an accretion time defined by the user. In our case, we arbitrarily choose $\Delta t=5 \mathrm{~s}$. Assuming the ice density is $\rho_{i c e}=917 \mathrm{~kg} \cdot \mathrm{m}^{-3}$ :

$$
h_{i c e}=\frac{\dot{m}_{i c e} * \Delta t}{\rho_{i c e}}
$$

\section{Considered Ice Crystals cloud characteristics}

HAIC/HIWC flight campaigns [12] gather an unprecedented quantity of data about Ice Crystals characteristics in Mesoscale Convective Systems providing.

In this paper, the HAIC/HIWC characterization was preferred to the Ice cloud characteristics available in the regulation material [13] since they differ in some aspects. For example the particle mean mass diameter (MMD) is assumed to be $200 \mu \mathrm{m}$ in [13] whereas in [12] it is shown that despite some variations, its value is larger in general.

In order to suit the input format of SPARTE, the raw characterization of the Ice Crystals particles from the HAIC/HIWC campaigns had to be adapted and simplified. Mainly, instead of a contentious PSD the considered PSD in those simulations is piecewise constant (see chapter V.B).

\section{Study of a generic engine Inlet \& Fan in ICI conditions}

The following section outlines the study of a generic engine Inlet \& Fan flying in ICI conditions. The goal is to determine potential effects of scooping, centrifugation and ice particle breakup on the local quantity of ice in the flow as well as on the PSD at the entrance of the engine and downstream the fan. In addition, a sensitivity study is performed in order to highlight the influence of the atmospheric particles diameter and sphericity.

\section{A. Description of the geometry and mesh}


The studied geometry was freely adapted from two separate engine inlet and fan geometries available in the literature [14] [15]. Those selected geometries are not designed to work together and come from two distinct origins. The purpose of this paper is not to study their potential adaptation so the aerodynamic conditions will not be detailed any further. Some arbitrary geometric modifications were necessary, for example the inlet was scaled so that its diameter fits the diameter of the fan. Also, a spinner was added and drawn from scratch.
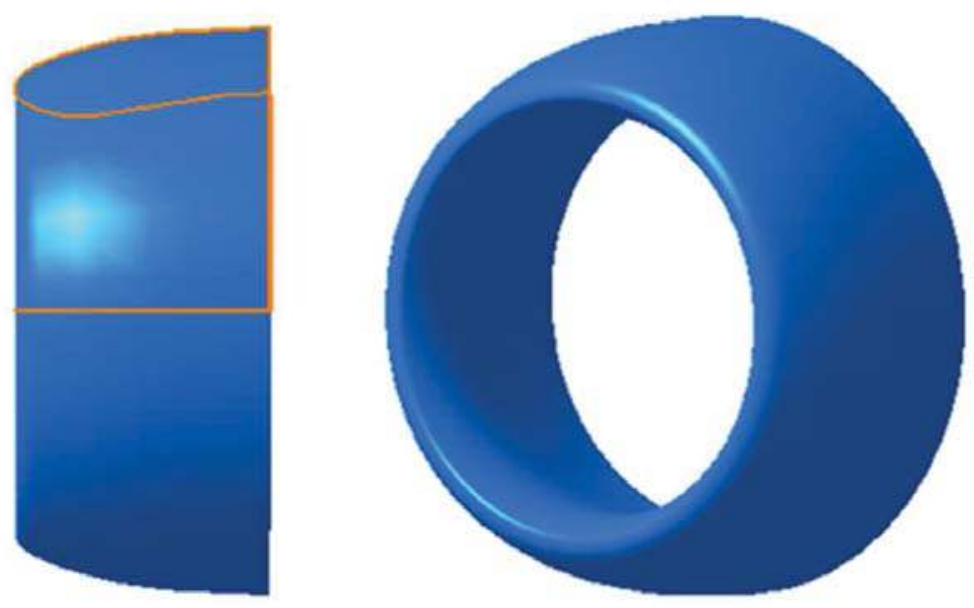

Fig. 1 Engine Inlet geometry adapted from [15].

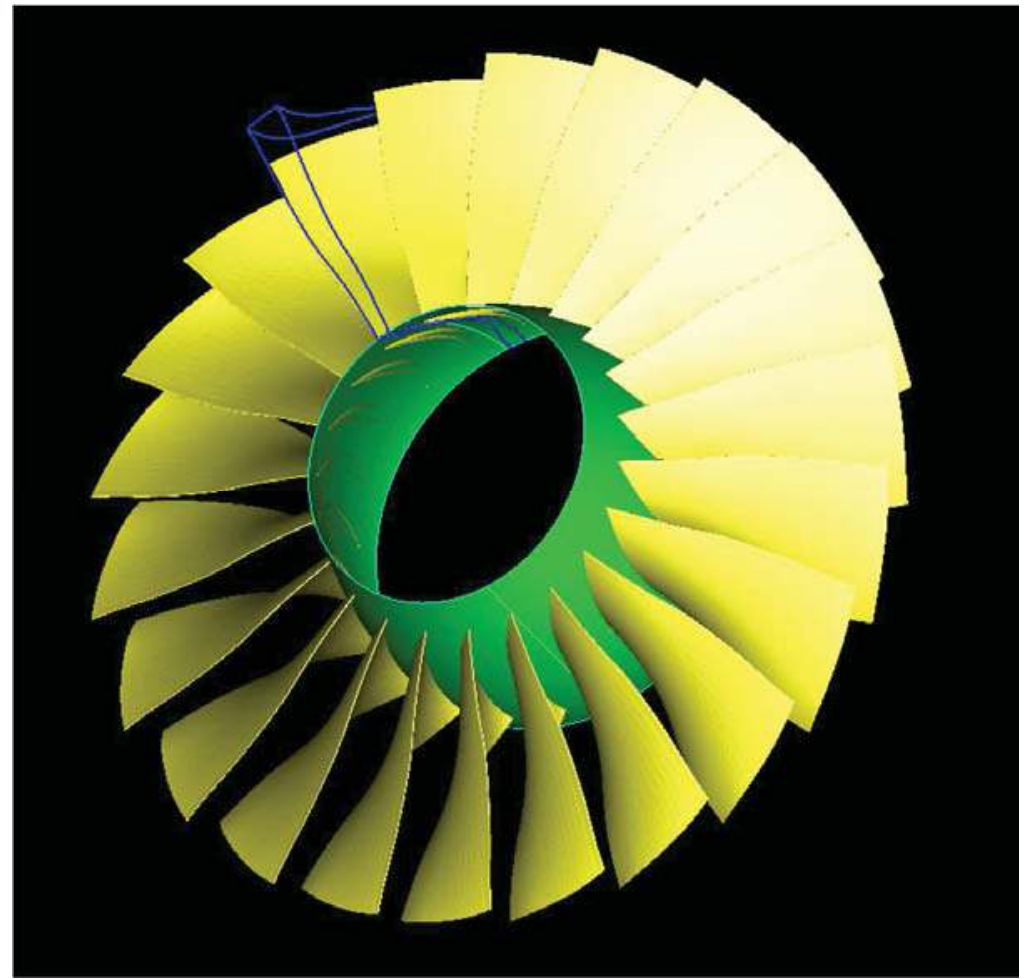

Fig. 2 Fan geometry adapted from [14]. 


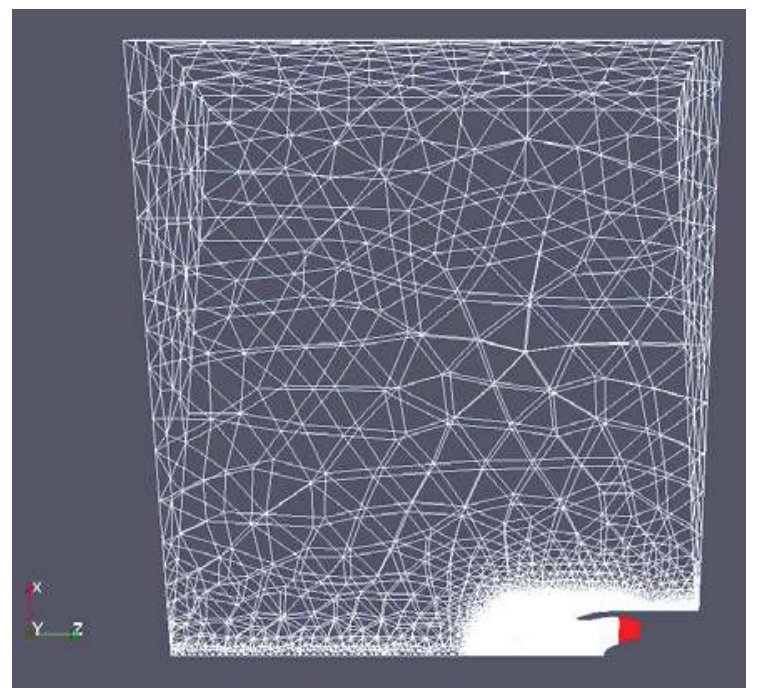

Fig. 3 View of the meshes of the studied domains. The inlet domain is meshed in white, the fan domain in red.

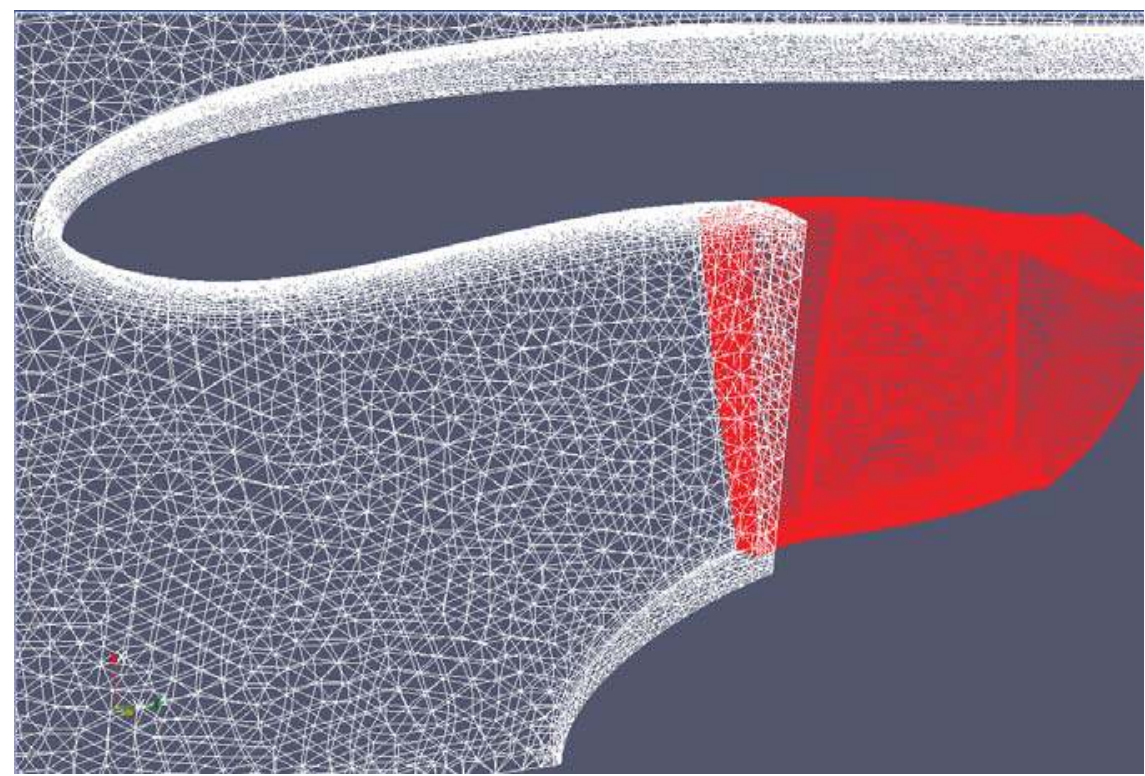

Fig. 4 Zoom of the meshes of the studied domains. The inlet domain is meshed in white, the fan domain in red.

The inlet and fan domains were not meshed with the same tool. The inlet domain was meshed using the ICEM non-structured mesher [16] whereas the fan domain was meshed using NUMECA Autogrid5 [17] structured mesher. For each domain, only one sector was meshed, the rest of the subdomain being determined by periodicity. There is a mixing plane between the two domains.

\section{B. Description of the flight and environment conditions}

Flight conditions representative of a cruise phase at an altitude of $35 \mathrm{kft}$, an ambient temperature of $-42.5^{\circ} \mathrm{C}$ and a Mach number of 0.74 are simulated in this study. Fig. 5 shows that these flight conditions are in the middle of the ICI envelope defined in regulation material (FAA Code of Federal Regulations (CFR) Part 33, Appendix D and EASA Certification Specification (CS) 25, Appendix P). 


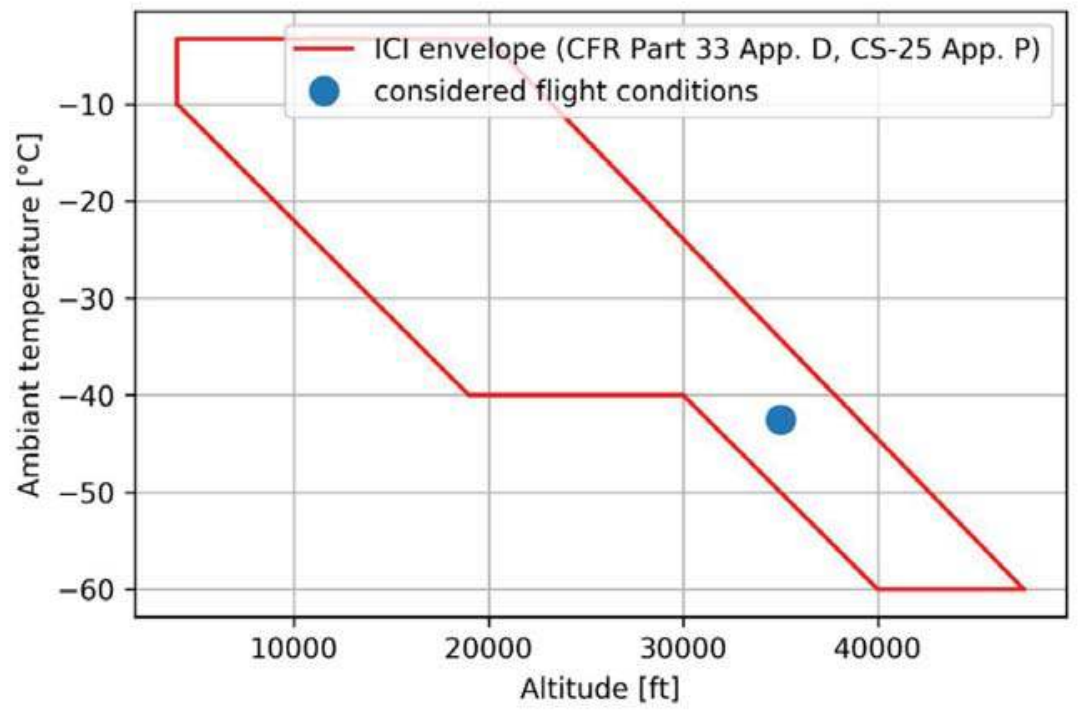

Fig. 5 Considered flight conditions in the ICI envelope

The atmospheric Ice Crystals conditions are chosen to be consistent with those measured during the HAIC/HIWC flight campaigns [12] in terms of IWC, PSD and sphericity. Fig. 6 shows the assumed PSD in the atmosphere for this study. It is composed of twelve classes of Ice Crystals discriminated by their diameter, each class is made of identical particles but represents a different mass fraction as shown in Fig. 6. Globally, the MMD of the assumed PSD is $400 \mu \mathrm{m}$. The IWC is set to $3.25 \mathrm{~g} \cdot \mathrm{m}^{-3}$ and the sphericity to 0.8 .

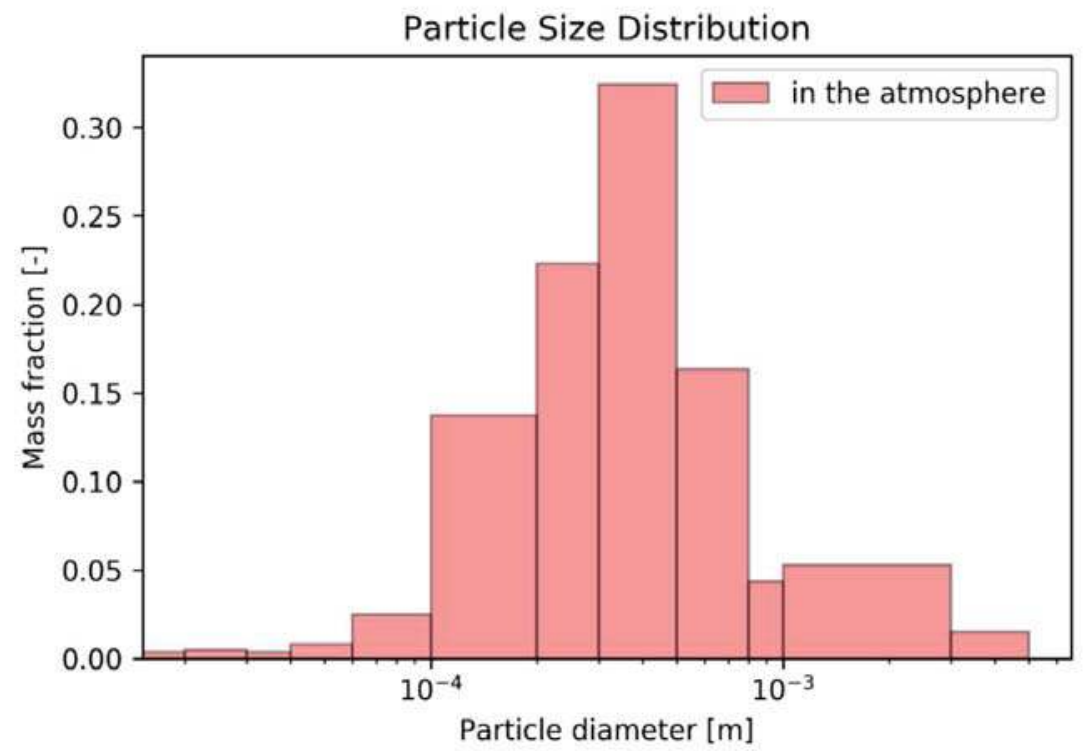

Fig. 6 Input Ice Crystals particle size distribution assumptions for the current study

Additionally, sensitivity studies are performed to determine the distinct influences of the particle diameters and of the particle sphericities.

Below are the considered particles diameters with a constant sphericity of 0.8 and a constant IWC of 3.25 g.m.

- Homogeneously distributed monodispersed particles of $20 \mu \mathrm{m}$,

- Homogeneously distributed monodispersed particles of $100 \mu \mathrm{m}$,

- $\quad$ (reference) Homogeneously distributed monodispersed particles of $200 \mu \mathrm{m}$,

- Homogeneously distributed monodispersed particles of $500 \mu \mathrm{m}$,

- Homogeneously distributed monodispersed particles of $1000 \mu \mathrm{m}$. 
Below are the considered sphericity values with homogeneously distributed monodispersed particle diameter of $200 \mu \mathrm{m}$ and a constant IWC of $3.25 \mathrm{~g} \cdot \mathrm{m}^{-3}$ :

- $\quad$ Particles sphericity of 0.2 ,

- $\quad$ (reference) Particles sphericity of 0.8 ,

- $\quad$ Particles sphericity of 1.0 .

\section{Results and analysis}

Preliminary calculations results show that particles whose diameter is larger than $100 \mu \mathrm{m}$ clearly seem to follow similar and mainly ballistic trajectories. For such big particles the mass flow rate that enters the engine does not depend on the particle diameter. This also implies a lot of particle breakup and bouncing and entails a strong influence of the flow path curvature.

\section{Particles trajectory in representative conditions}

Fig. 7 shows Ice Crystals particles trajectories and size evolution across the studied Inlet \& Fan in cruise phase for a distribution which is representative of realistic atmospheric conditions. This configuration is close to what can be encountered during a flight in an Ice Crystals cloud. In this figure, one can see that some particles have the tendency to follow the streamlines and do thus not enter the engine. On the contrary, other particles seem to have a higher momentum and to follow a trajectory that is not influenced by the airflow. It seems that the particles hitting the inlet and bulb walls, resulting in bouncing and fragmentation, are of the latter kind. Further analysis of the results shows that no melting is observed across the inlet and fan which is not surprising since the temperatures in the area are still very low (around $-20^{\circ} \mathrm{C}$ downstream the fan) despite the temperature raise across the fan.

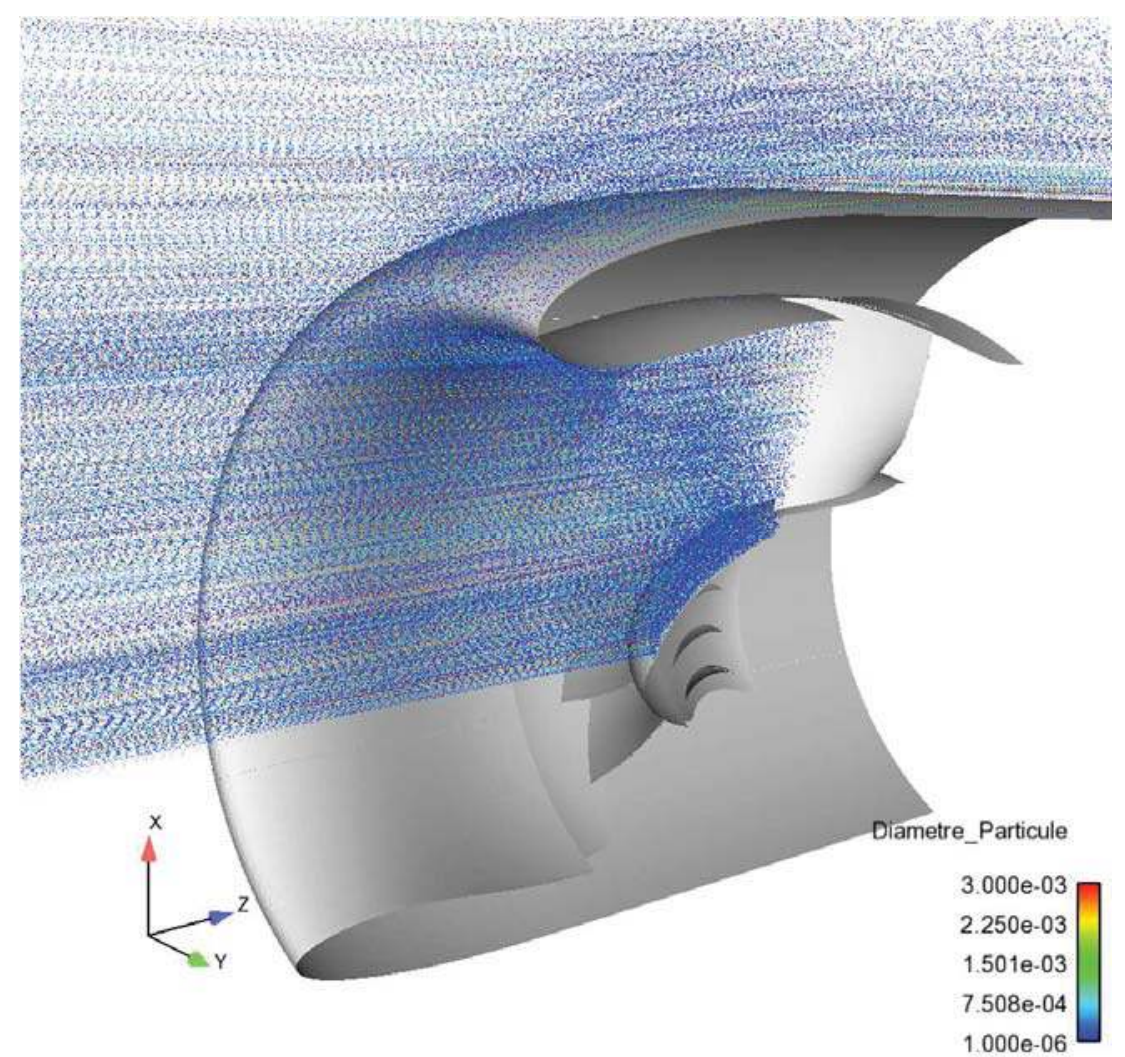

Fig. 7 Ice Crystals trajectories and size (in $\mathrm{m}$ ) across the studied Inlet in cruise phase for a realistic atmospheric PSD (for readability reasons only one sector is represented whereas half of the inlet \& fan is represented)

Fig. 8 shows superimposed PSD in three different locations. The calculations show little influence of the scoop effect on the PSD in the inlet section which is very similar to the PSD in the atmosphere. However, downstream the fan, the PSD is affected by the fragmentation on the fan bulb and blades. In this location, the MMD is reduced from $400 \mu \mathrm{m}$ to $150 \mu \mathrm{m}$. 


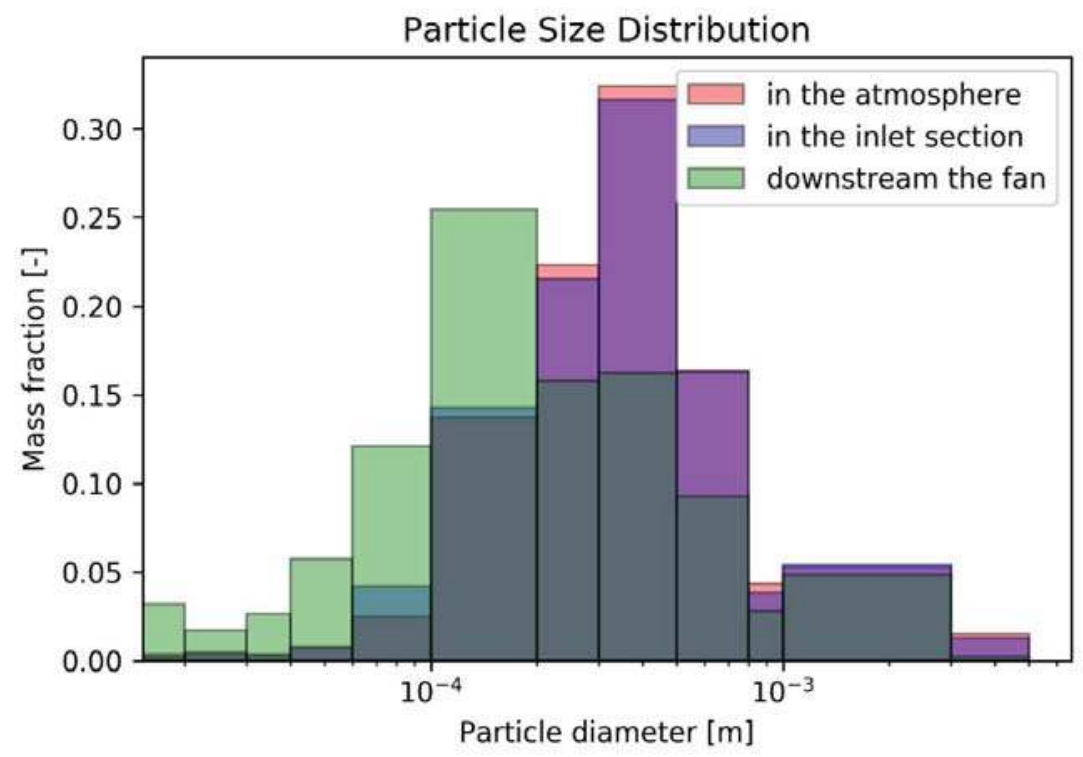

Fig. 8 Superimposed Ice Crystals PSD in three different locations: in the atmosphere, in the inlet section and downstream the fan

In terms of quantity of particles in the inlet flow, the calculations show a major influence of the scoop effect. Indeed, since most of the particles follow a ballistic trajectory, the major part of the Ice Crystals flow is not deviated by the air streamlines. Therefore, in the simulated conditions, the mass fraction of Ice Crystals particles in the inlet section is $1.5 \%$ whereas it is only $0.9 \%$ in the atmosphere. Note that this scoop effect depends much on the air flow rate entering the engine: for deferent flight phases, the resulting scoop effect may differ.

\section{Sensitivity study}

Fig. 9 shows a comparison of Ice Crystals trajectories and size across the studied inlet and Fan. For small particles $(20 \mu \mathrm{m})$ little bouncing and fragmentation is observed, particles mostly follow the streamlines. On the contrary the large particle $(1 \mathrm{~mm})$ ballistic trajectory which implies a lot of bouncing and fragmentation, mostly on the fan bulb and blades. This observation confirms those made in the previous paragraph.
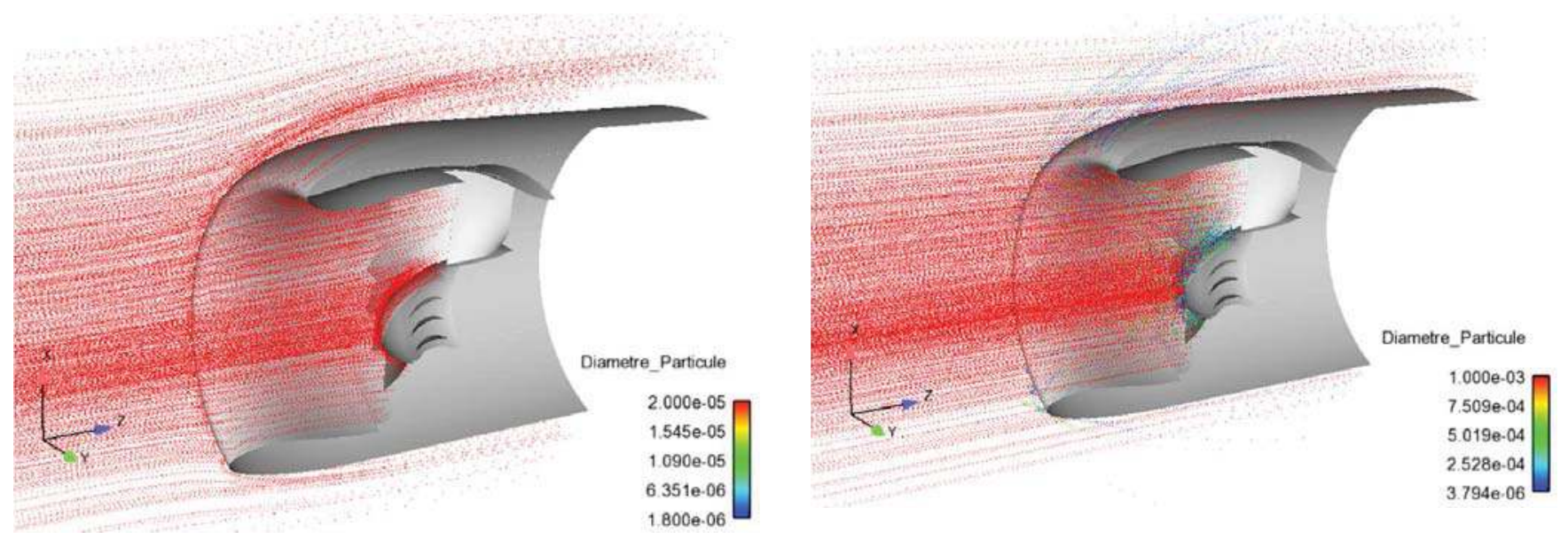

Fig. 9 Comparison of Ice Crystals trajectories and size (in $\mathbf{m}$ ) across the studied Inlet \& Fan in cruise phase for a homogeneously distributed monodispersed particle diameter of $20 \mu \mathrm{m}$ (left) and $1 \mathrm{~mm}$ (right).

Fig. 10 shows more results from the particles diameter influence study. Particles whose diameter is larger than $100 \mu \mathrm{m}$ clearly seem to follow similar trajectories. For such big particles the mass flow rate that enters the engine does not depend on the diameter. On the other side of the particle size spectrum, small particles seem to follow the streamlines and many of them are deviated. Consequently, for $20 \mu \mathrm{m}$ diameter particles, the quantity of ice crystals that enters the engine is significantly smaller than for bigger particles even though the concentration in the 
atmosphere is identical for all the cases run in this influence study. Also, this entails little impact with the walls and therefore little bouncing and fragmentation.

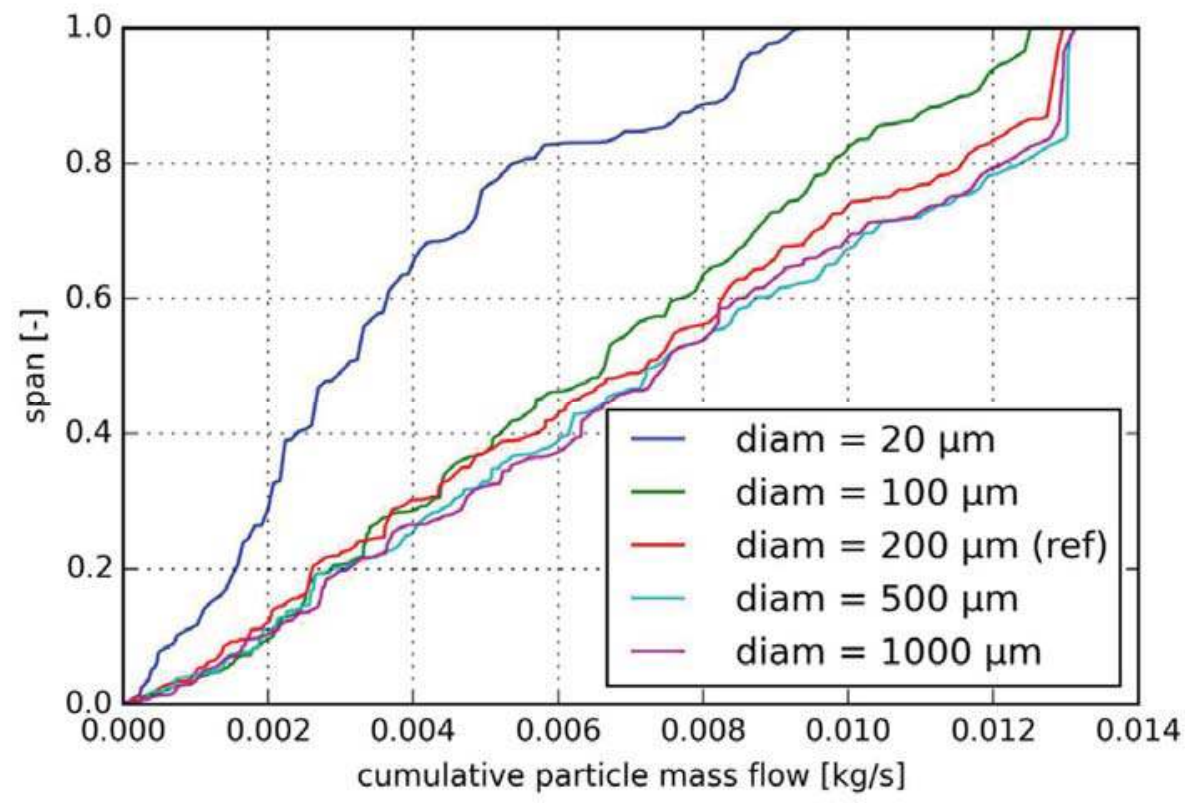

Fig. 10 Cumulative particle mass flow Vs span for different particles diameters across the mixing plane upstream the fan.

Finally, Fig. 11 shows that the sphericity of the particles does not have first order effect on their trajectories until a very low value such as 0.2 which is much too low with respect to realistic flight conditions

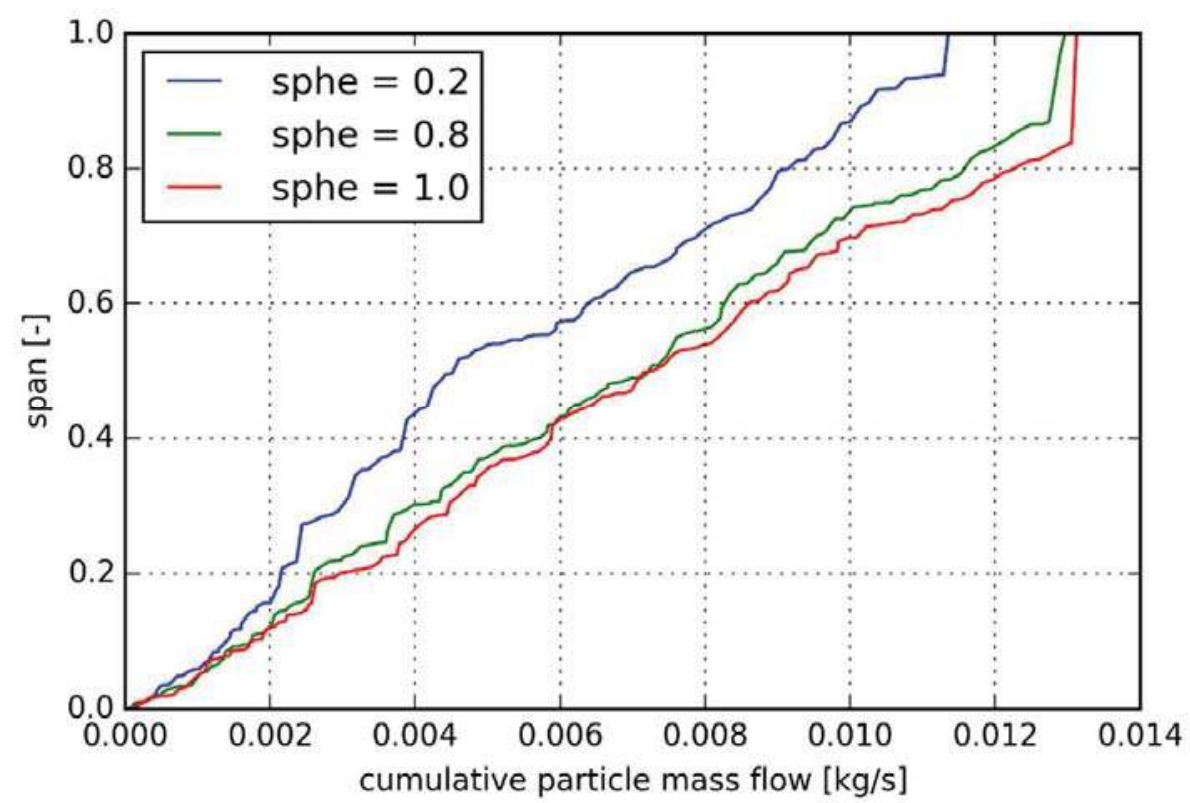

Fig. 11 Cumulative particle mass flow Vs span for different particles sphericities across the mixing plane upstream the fan

\section{Study of a Fan \& Booster in ICI conditions}

The present section is devoted to the description of calculations performed on a Fan \& Booster geometry representative of an aircraft engine flying in ICI conditions. The aim of this part is to have an insight on the row-by- 
row characteristics of the Ice Crystals particles flow: bulk and local concentrations, PSD, local impinging particles flow on each wall and the resulting impact regime (sticking, bouncing shattering).

According to the literature the melt ratio (LWC/TWC) is potentially a good Ice Crystal accretion indicator via the so-called plateau effect [18] [11]. Indeed, it has been experimentally observed that Ice Crystal accretion is more likely to occur when the LWC/TWC ratio lies within a certain range. Below a certain threshold and above another threshold, little Ice Crystals accretion occurs. This study is aimed at showing consistency of the calculation result with the plateau indicator first by identifying realistic flight conditions where Ice Crystals accretion occurs as well as other realistic flight conditions where Ice Crystals accretion does not occur, then by estimating the local LWC/TWC ratio in the area where Ice Crystals accretion is believed to occur and comparing the resulting ratios to thresholds of the plateau, while keeping in mind that those thresholds are not clearly defined.

Another objective of this study is to compare the row-by-row characteristics of the Ice Crystals particles flow between a case run with atmospheric Ice Crystals conditions consistent to those measured during the HAIC/HIWC flight campaigns and a case run with Ice Crystals conditions consistent to what is typically simulated in altitude test cells. By doing so, we contribute to show that even though the simulated conditions in altitude test cells is not totally consistent with the actual atmospheric conditions, the engine behaviour might be very similar.

\section{A. Description of the geometry and mesh}

The fan and spinner geometry described in paragraph $\mathrm{V}$ was considered again in this study. In addition, a new generic booster geometry was designed for the purpose of this article. This booster is as simple as possible and is made of a first row of 117 static blades designated as the Input Guide Vane (IGV), a rotating row of 125 blades and a second row of 117 static blades designated as the Exit Guide Vane (EGV). No aerodynamic optimization of the airfoils was performed since the present stydy focuses on particle tracking. However we made sure that pressure and temperature rise across the fan and booster were sufficient to yield air flow conditions prone to Ice Crystals accretion.

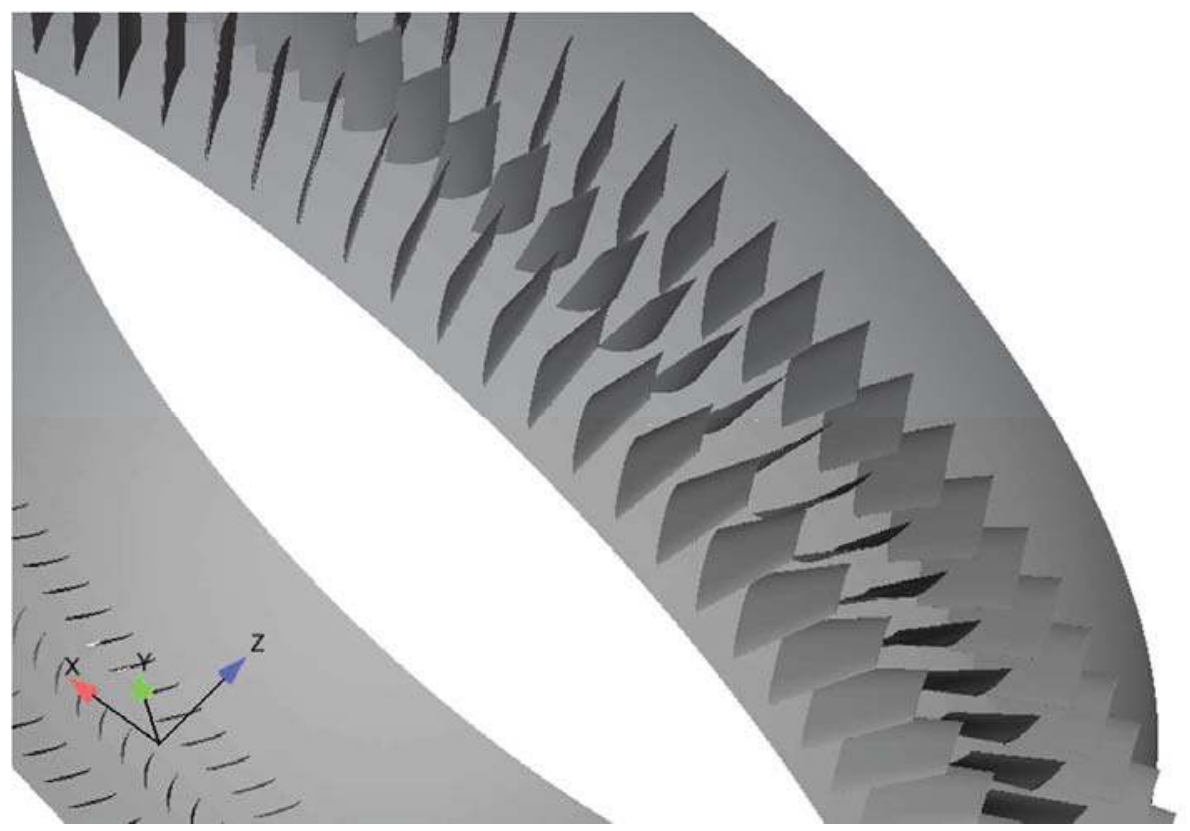

Fig. 12 View of the blades and hub of the booster considered in the current study 


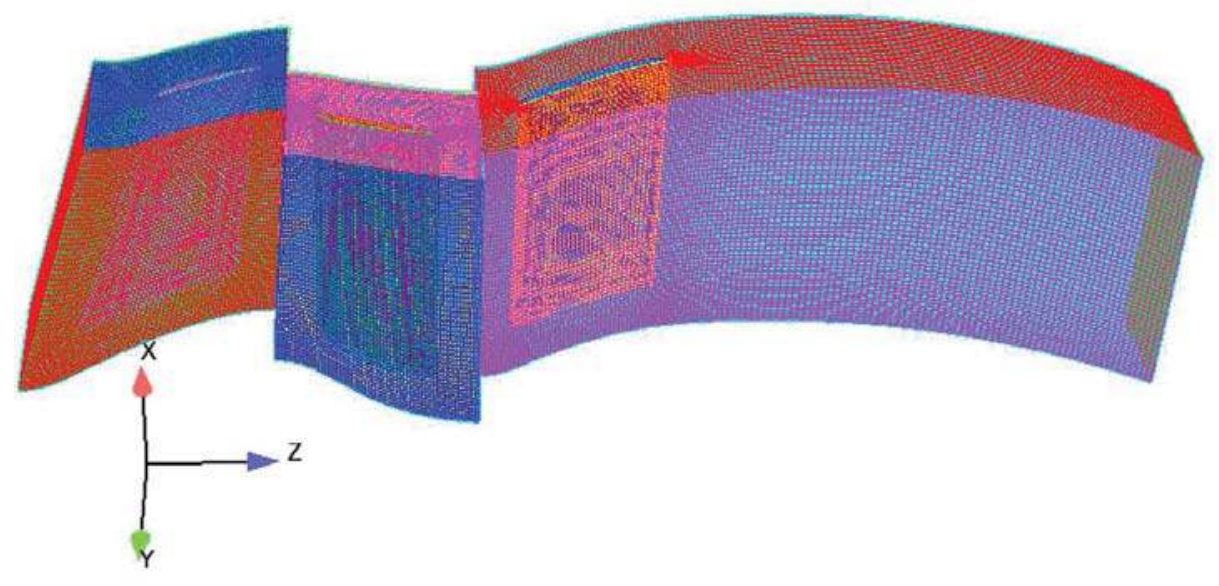

Fig. 13 View of the meshes of the booster domains: IGV, rotor row and EGV (the fan is not represented in this figure)

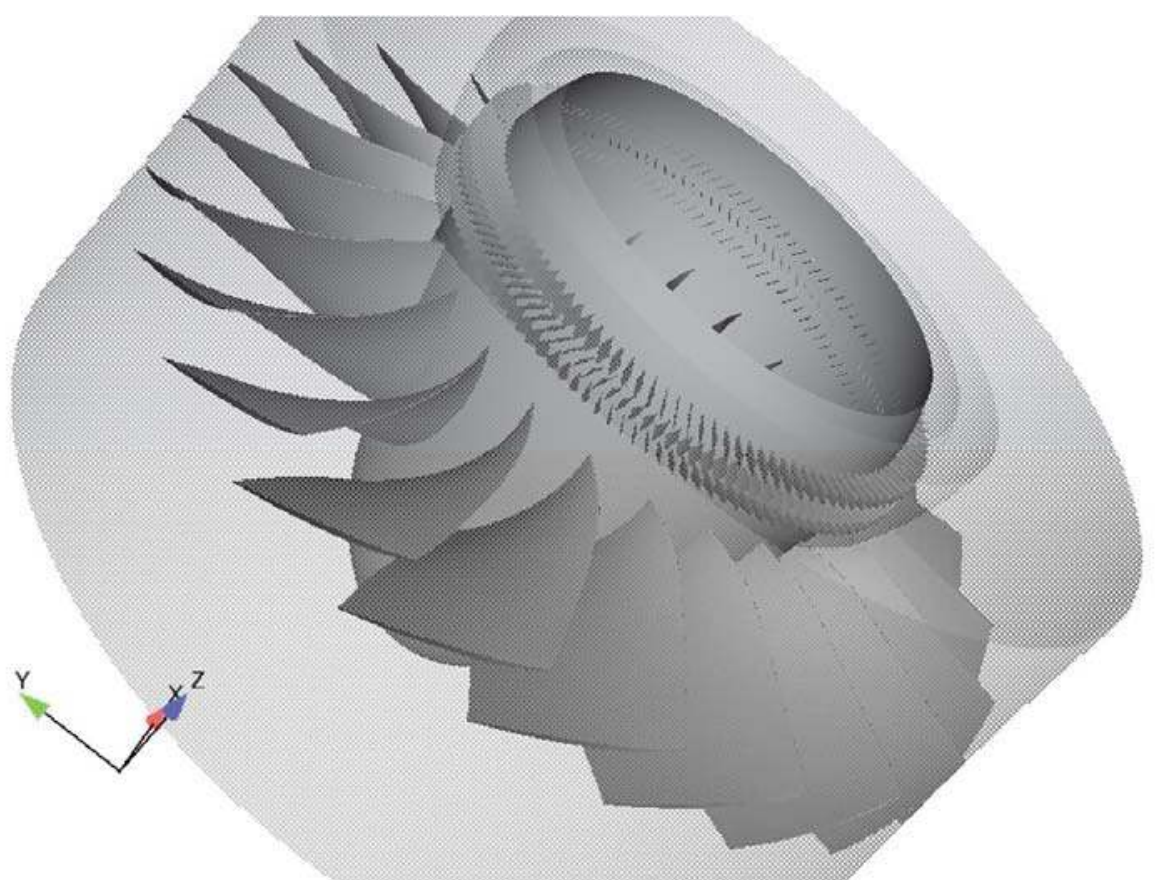

Fig. 14 General view of the fan and Booster considered for the current study (shroud and nozzle are displayed in transparency) 


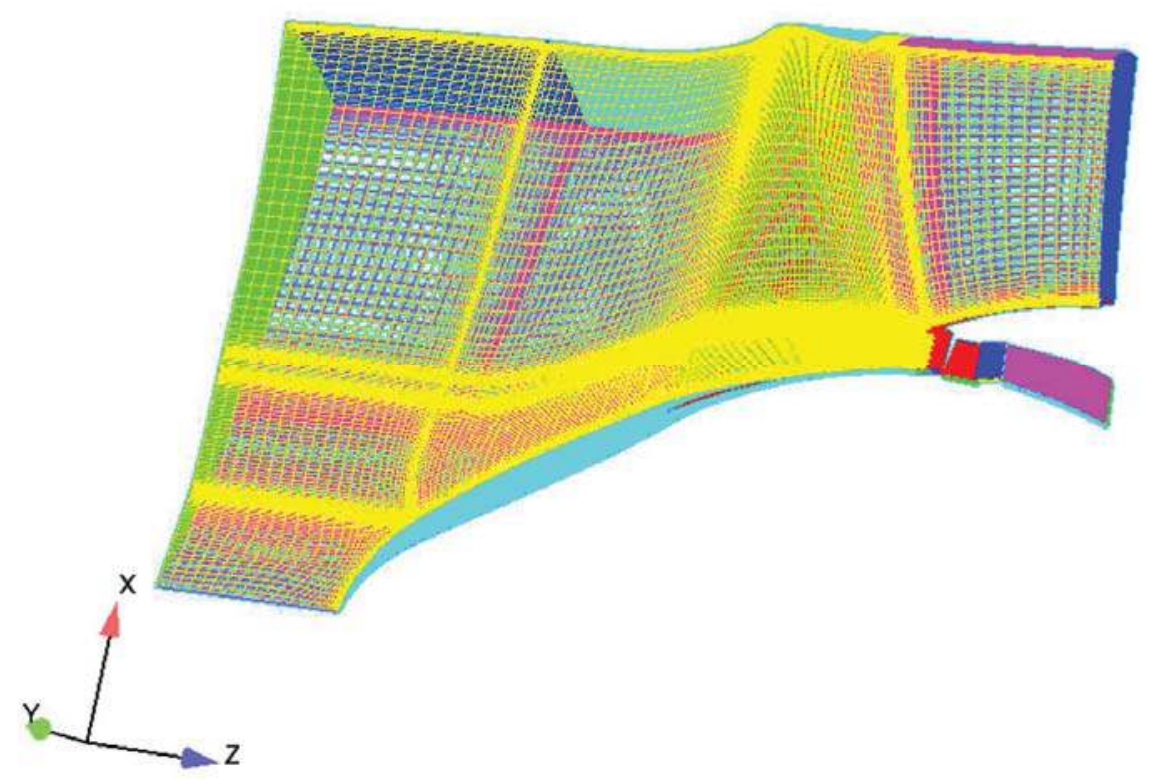

Fig. 15 View of the meshes of the studied domains (fan and booster)

Even though CEDRE is natively able to deal with non-structured grids the fan and booster were meshed with NUMECA's Autogrid5 [17] structured tool to guarantee a good mesh quality. For each row, only one blade was meshed, the rest of the subdomain being determined by periodicity. There are three mixing planes in the domain, between the fan and IGV, between the EGV and the rotating row and between the rotating row and the EGV.

\section{B. Description of the flight and environment conditions}

Calculations are run for flight conditions representative of cruise phase at an altitude of $35 \mathrm{kft}$ and Mach number of 0.74. Different atmosphere static temperatures are considered.

The input boundary Ice Crystals conditions are chosen to be consistent with those calculated in part V of this paper in terms of IWC, PSD and sphericity in order to be representative of inflight conditions. The PSD and sphericity are then chosen to be similar to the atmospheric PSD and sphericity. Due to the important scoop factor observed in the previous section, the IWC in the inlet section is much bigger than the one in the atmosphere and set to $6.6 \mathrm{~g} / \mathrm{m}^{3}$. For simplicity sake, it is assumed that the particles velocity field is the same as the air flow velocity, this assumption is an over simplification since the actual particles velocity field is different.

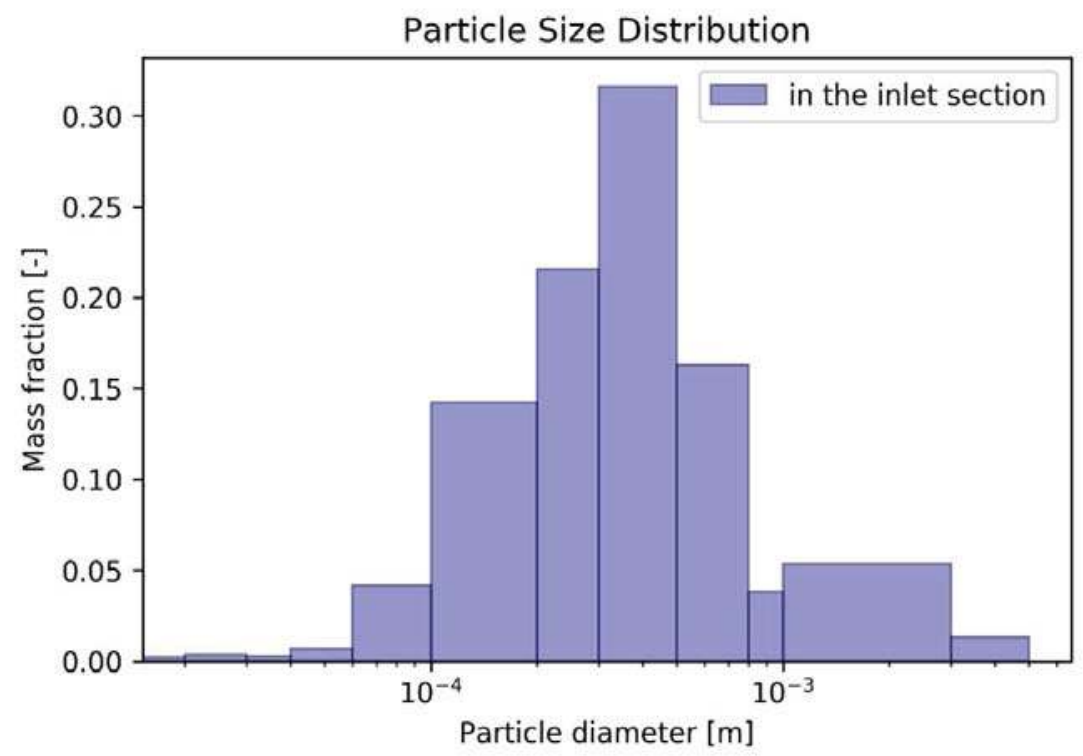

Fig. 16 Input Ice Crystals particle size distribution assumptions for the current study 
Additional trajectory calculations are performed for particle diameters and sphericities representative of those that can be generated in altitude test cells such as Nasa PSL [19] [20]. In general those are smaller and more homogeneous than what can be encountered in flight. In this study, we considered a monodispersed $80 \mu \mathrm{m}$.

\section{Results and analysis}

3. Calculations in representative conditions

Experimental studies [18] [11] [21] indicate that the liquid water content LWC to the total water content TWC of the flow has a major influence on the accretion severity. According to these studies, the ratio at which the icing is severest ranges from approximately 10 to $25 \%$.

Fig. 17 shows melting ratio as calculated by SPARTE at different stations across the studied Fan \& Booster. One can observe that in most locations the particles remain fully glaciated.

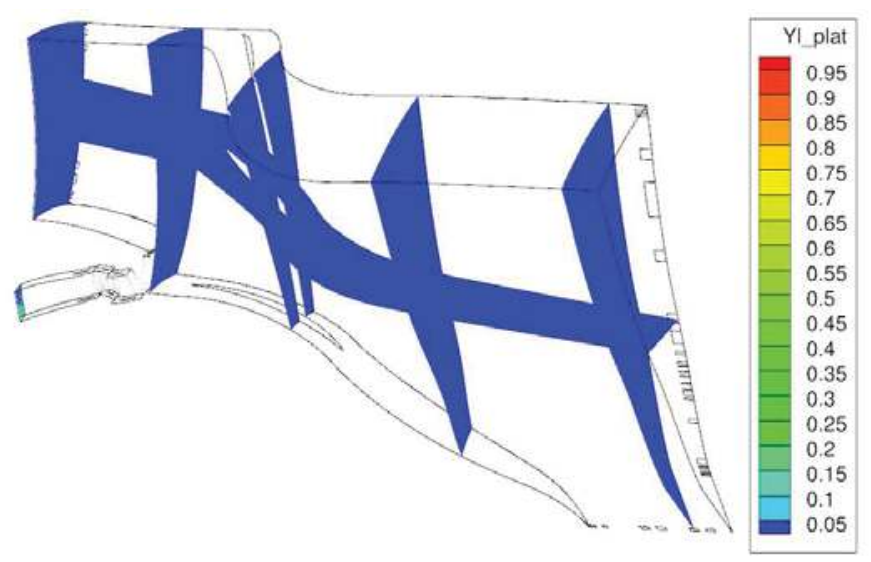

Fig. 17 melting ratio at different stations across the studied Fan \& Booster. Only one sector per stage is represented. The inlet section is on the right of the picture

In Fig. 18 and Fig. 19 we have a closer look at the booster only. The melting ratio increases in the EGV stage, reaching values that are in the plateau range, indicating that accretion should occur.
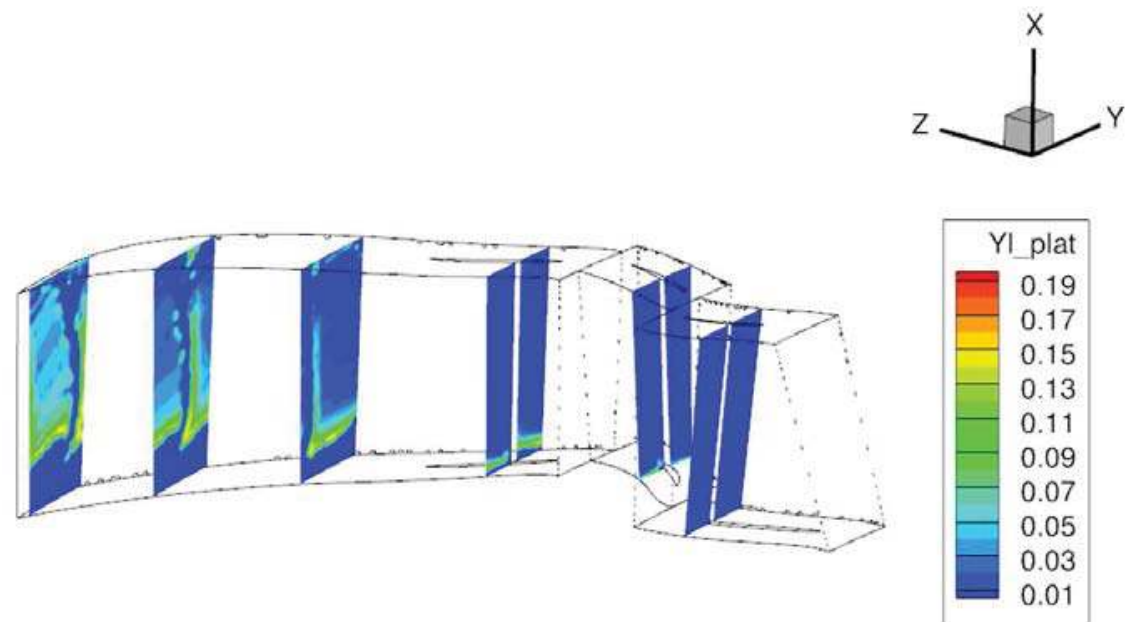

Fig. 18 melting ratio at different stations across the studied Booster. Only one sector per stage is represented. The IGV is in the right side of the image, the EGV is on the left side. 

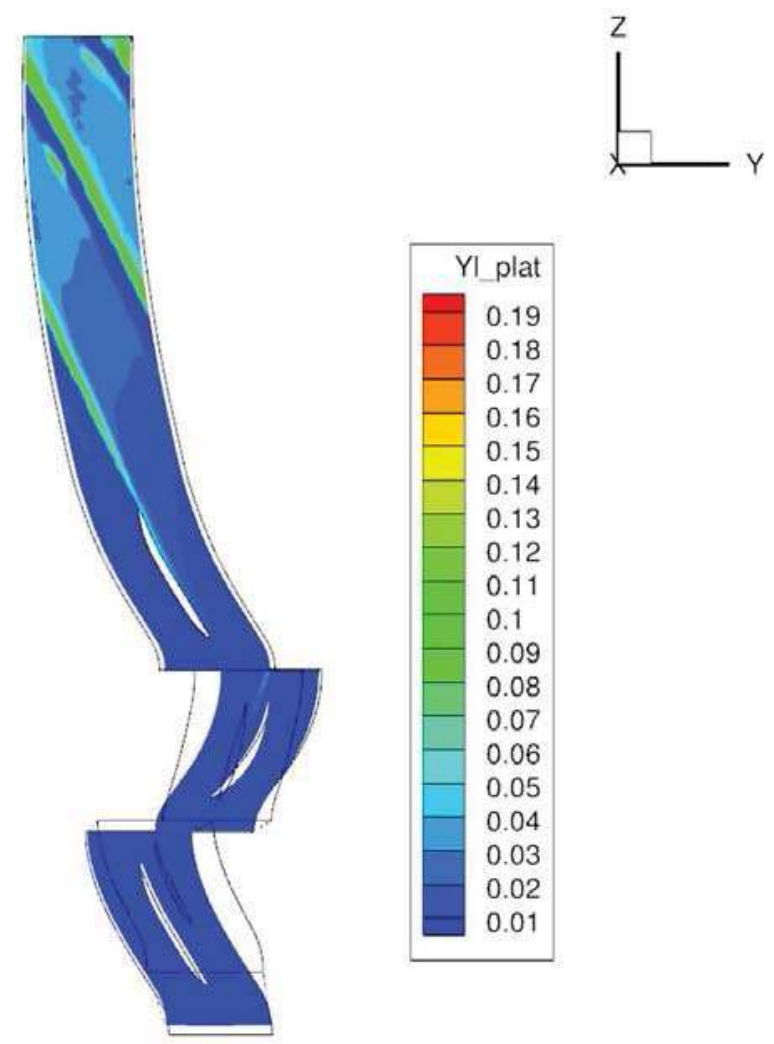

Fig. 19 melting ratio at the outer diameter of the studied Booster for the reference case. Only one sector per stage is represented. The IGV is in the bottom side of the image, the EGV is on the top side.

The result of the application of the ice thickness calculation method described in paragraph III.D is shown in Fig. 20. Minor accretion is visible on the EGV blade, but major accretion is observed on the outer diameter of the vane.

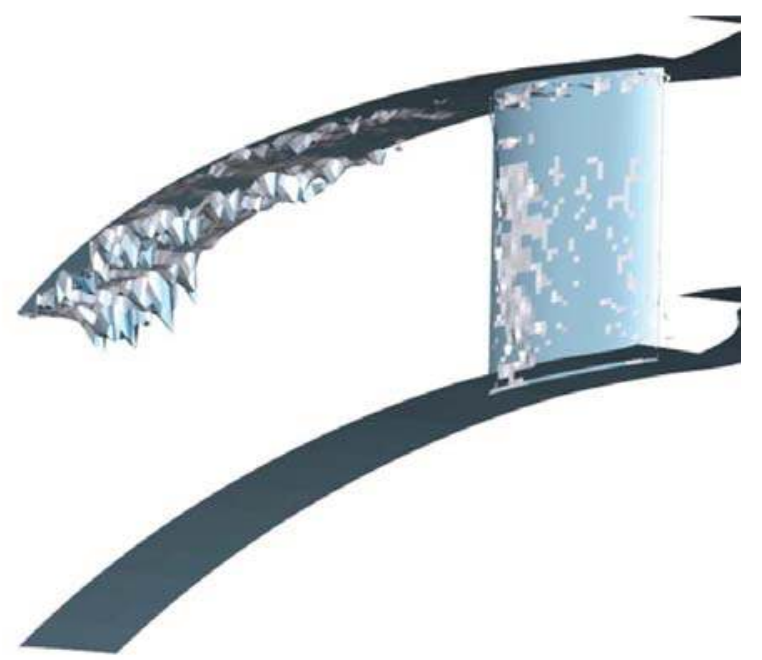

Fig. 20 approximation of the accreted ice thickness in the EGV stage for the reference case.

\section{Sensitivity study}

This section presents a comparison between a case run with Ice Crystal conditions consistent to what is measured in high altitude and one which corresponds to a typical simulation in altitude test cells where the PSD is different than the one in the atmosphere (smaller particles, narrower distribution). By doing such sensitivity study, we want to quantify the difference between what can be simulated in altitude test cells with the actual atmospheric conditions. 
Fig. 21 to Fig. 24 show comparisons of the PSD for both calculation at different sections across the studied Fan $\&$ Booster. One can see that the PSD of the two different particles flows are getting closer to each other as they evolve in the engine. However, when the Ice Crystals reach the EGV stage, even though in both cases the particles have been heavily fragmented in the upstream stages, their MMD remain a little different: in the monodisperse case, the MMD went from $80 \mu \mathrm{m}$ in the inlet section to $10 \mu \mathrm{m}$ at the exit of the engine whereas in the representative case the MMD went from $400 \mu \mathrm{m}$ to $40 \mu \mathrm{m}$.

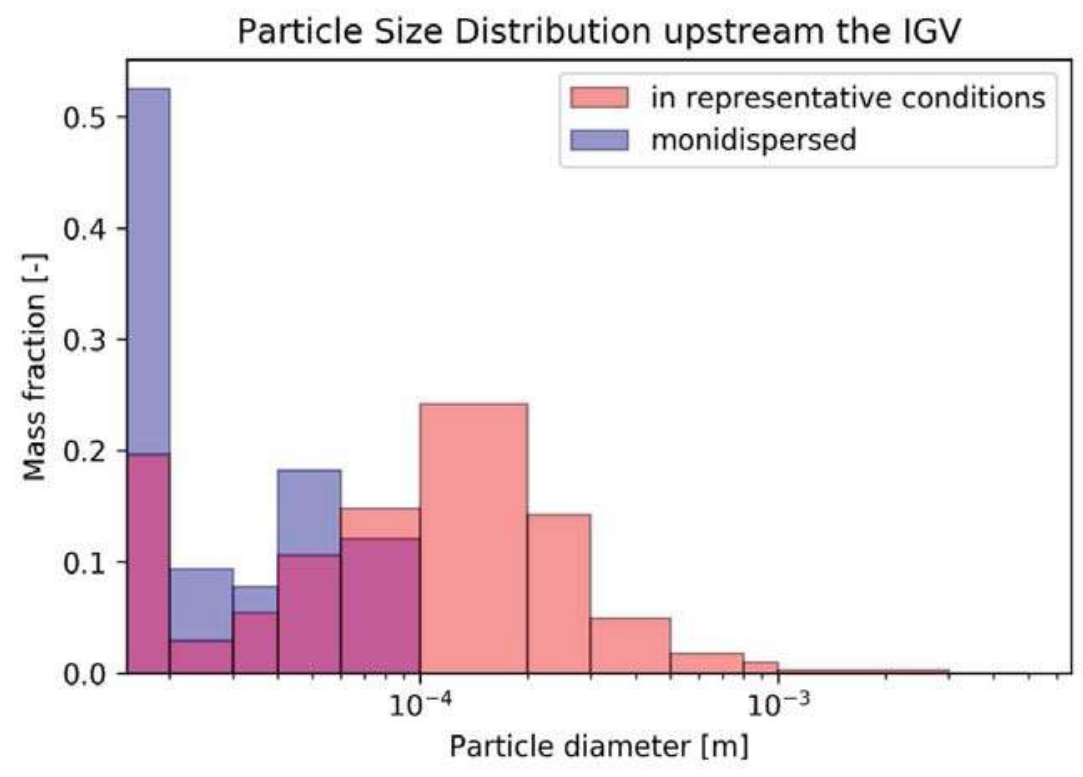

Fig. 21 Superimposed Ice Crystals PSD in the primary flow upstream the IGV for two different PSD assumptions: one in conditions representative of realistic environment, one for an $80 \mu \mathrm{m}$ monodispersed distribution

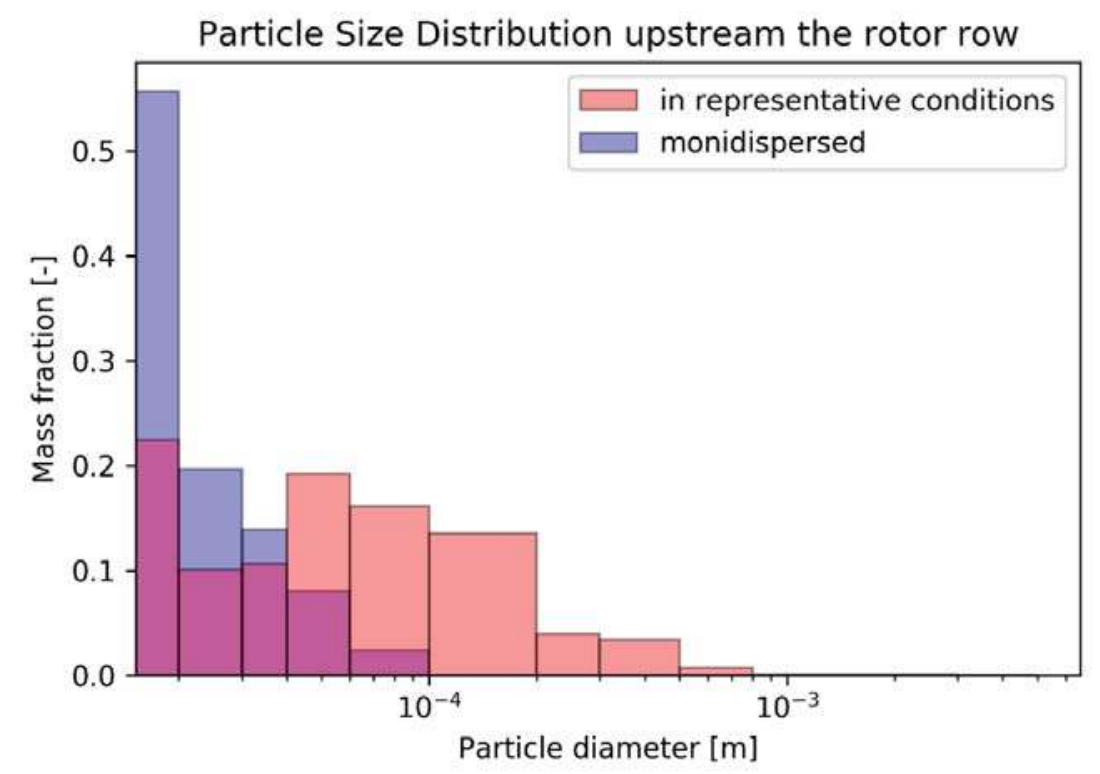

Fig. 22 Superimposed Ice Crystals PSD in the primary flow upstream the rotating row for two different PSD assumptions: one in conditions representative of realistic environment, one for an $80 \mu \mathrm{m}$ monodispersed distribution 


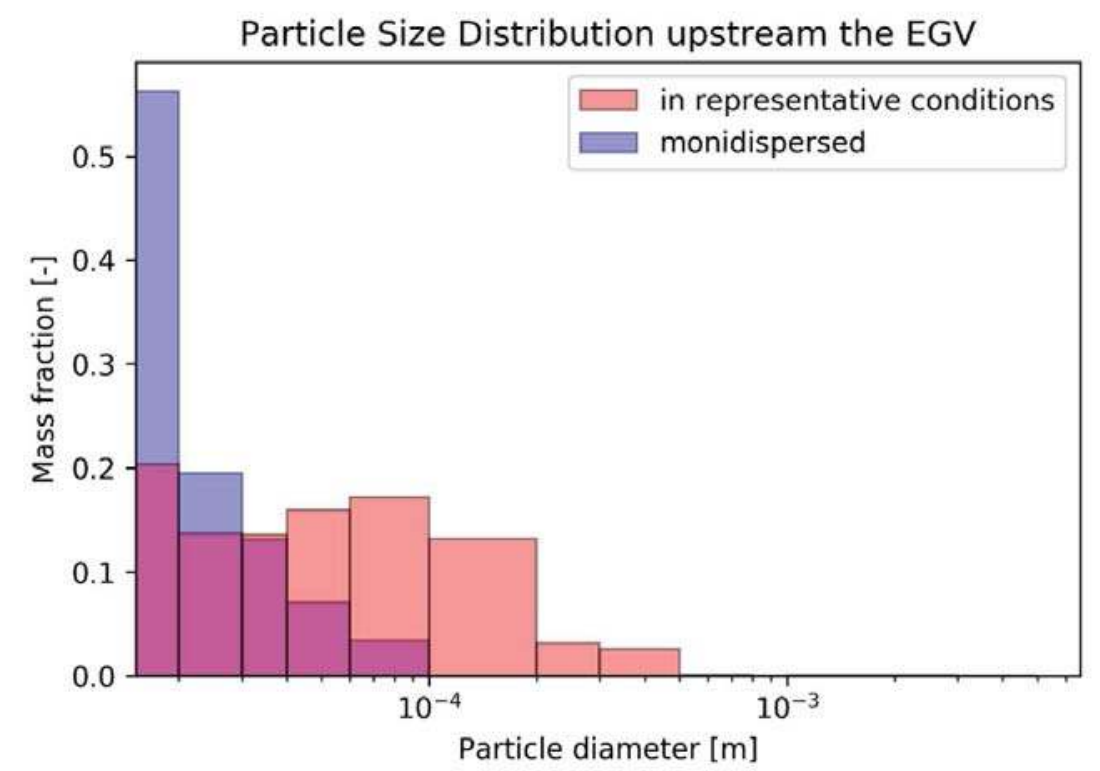

Fig. 23 Superimposed Ice Crystals PSD in the primary flow upstream the EGV for two different PSD assumptions: one in conditions representative of realistic environment, one for an $80 \mu \mathrm{m}$ monodispersed distribution

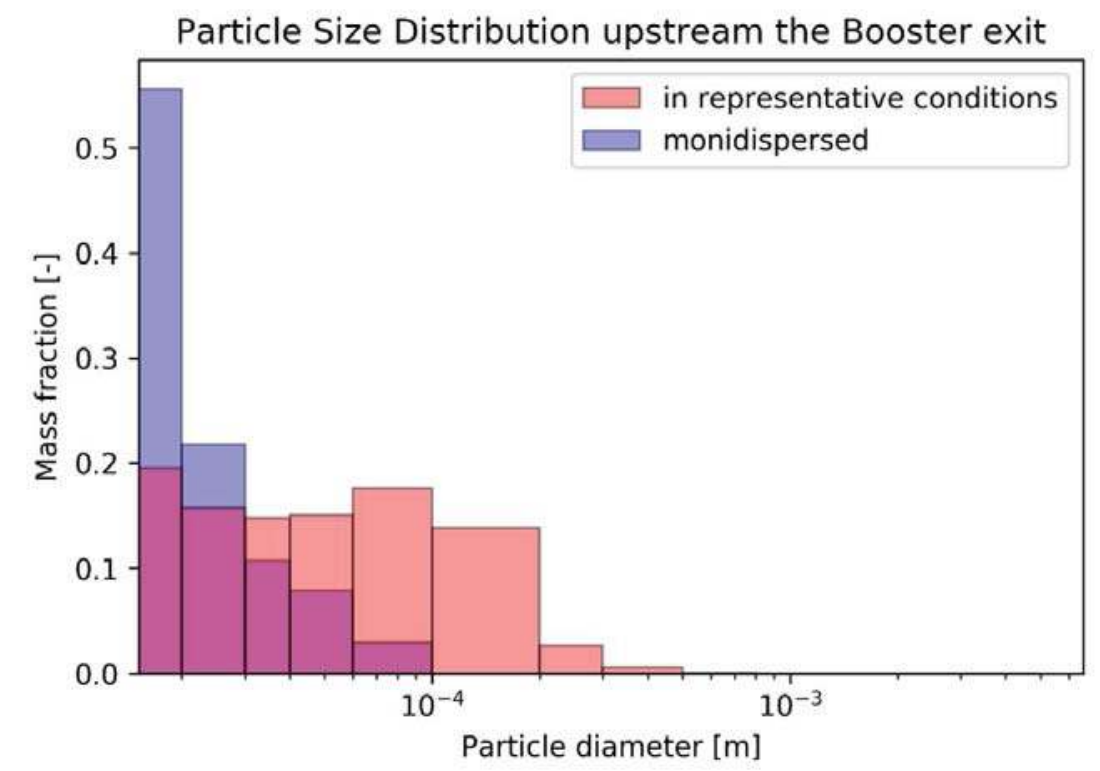

Fig. 24 Superimposed Ice Crystals PSD in the primary flow upstream the Booster exit for two different PSD assumptions: one in conditions representative of realistic environment, one for an $80 \mu \mathrm{m}$ monodispersed distribution

For both calculations, identical concentration were imposed in the inlet section. According to the calculations the total mass fraction of water (liquid and solid) at the exit section is $1.06 \%$ in the representative case. In the monodisperse the total water mass fraction is $0.92 \%$.

\section{Conclusion}

In this paper, we showed the recent progress of numerical tools used at Safran Aircraft Engines to simulate Ice Crystals trajectories. Engine manufacturers such as Safran Aircraft Engines can now estimate, in real flight conditions, the quantity of Ice Crystals that enters their engines and the quantity of particles that is deviated. They can calculate the PSD at any section as well as the liquid and solid fraction in the particle flow. Finally they can approximate the impinging particles on any wall. 
Even though simulation results are in the expected orders of magnitude and provide qualitative conclusions that compare favorably with experimental observations, this study does not provide any quantitative validation since it is only based on purely numerical test cases and since it relies on hypothetical, though realistic, flight conditions.

Finally, this study shows the need for improved accretion models. Indeed, trajectory tools are necessary to assist engine makers in the design process of their products but they are not sufficient to accurately estimate the Ice Crystals Icing threat. The ice thickness calculation method used in this paper is helpful for qualitative conclusions but does not take into account phenomena that are believed to be fundamental in the accretion process such as heat exchange with the wall, erosion or water runback.

\section{References}

[1] P. Villedieu, P. Trontin and R. Chauvin, "Glaciated and mixed-phase ice accretion modeling using ONERA 2D icing suite," in 6th AIAA Atmospheric and Space Environments Conference, 2014.

[2] P. Trintin, G. Blanchard and P. Villedieu, "A comprehensive numerical model for mixed-phase and glaciated icing conditions," in 8th AIAA Atmospheric and Space Environments Conference, 2016.

[3] A. Baumert, S. Bansmer, P. Trontin and P. Villedieu, "Experimental and numerical investigations on aircraft icing at mixed phase conditions," International Journal of Heat and Mass Transfer, no. 123, pp. 957-978, 2018.

[4] E. Norde, J. Senoner, E. v. d. Weide, P. Trontin, H. Hoeijmakers and P. Villedieu, "Eulerian and Lagrangian Ice Crystal Trajectory Simulations in a Generic Turbofan Compressor," AIAA Journal of Propulsion and Power, In press, 2018.

[5] L. Hervo, J. Senoner, A. Biancherin and B. Cuenot, "Large-Eddy Simulation of Kerosene Spray Ignition in a Simplified Aeronautic Combustor," Flow, Turbulence and Combustion, available online, 2018.

[6] G. H. Ganser, "A Rational Approach to Drag Prediction of Spherical and Nonspherical Particles," Powder Technology, vol. 77, no. 2, pp. 143-152, 1993.

[7] T. Hauk, E. Bonaccurso, P. Villedieu and P. Trontin, "Theoretical and Experimental Investigation of the Melting Process of Ice Particles," Journal of Thermophysics and Heat Transfer, vol. 30, no. 4, pp. 946-954, 2016.

[8] T. Hauk, R. I. and C. Tropea, "Ice particle Collision with a Dry Rigid Substrate and its Breakup," in SAE meeting, Prague, 2015.

[9] H. T., I. Roisman and C. Tropea, "Investigation of the impact behavior of ice particles," in 6th AIAA Atmospheric and Space Environment, Atlanta, 2014.

[10] A. Refloch, B. Courbet, A. Murrone, P. Villedieu, C. Laurent, P. Gilbank, J. Troyes, L. Tessé, G. Chaineray, J. Dargaud, E. . Quemerais and F. Vuillot, AerospaceLab 5, CFD platforms and Coupling, ONERA, 2011.

[11] T. C. Currie, D. Fuleki and A. Mahallati, "Experimental studies of mixed-phase sticking efficiency for ice crystal accretion in jet engines," in 6th AIAA Atmospheric and Space Environments Conference, 2014.

[12] D. Leroy, P. Coutris, F. Emmanuel, A. Schwarzenboeck, J. W. Strapp, L. E. Lilie, A. Korolev, G. McFarquhar, F. Dezitter and A. Grandin, "HAIC/HIWC field campaigns - Specific findings on ice crystals characteristics in high ice water content cloud regions," in 8th AIAA Atmospheric and Space Environments Conference, 2016.

[13] Federal Aviation Administration, AC 20-147A, 2014.

[14] A. J. Strazisar, J. R. Wood and M. D. Hathaway, Laser anemometer measurements in a transonic axial-flow fan rotor, 1989.

[15] M. Papadakis, G. W. Zumwalt, R. Elangonan, G. A. Freund Jr, M. Breer and L. Whitmer, An Experimental Method for Measuring Water Droplet Impingement Efficiency on Two-and Three-Dimensional Bodies, 1989.

[16] ANSYS, Introduction to ANSYS ICEM CFD v16.2, 2015.

[17] Numeca international, User Manual AutoGrid v9, 2013.

[18] T. C. Currie, D. Fuleki and D. C. Knezevici, "Altitude scaling of ice crystal accretion," in 5th AIAA Atmospheric and Space Environments Conference, 2013.

[19] L. E. Steen, R. F. Ide, J. F. Van Zante and W. J. Acosta, "NASA Glenn Icing Research Tunnel: 2014 and 2015 Cloud Calibration Procedures and Results," NASA, 2015. 
[20] P. M. Struk, T. P. Ratvasky, T. Bencic, J. F. Van Zante, M. C. King, J. C. Tsao and T. P. Bartkus, "An Initial Study of the Fundamentals of Ice Crystal Icing Physics in the NASA Propulsion Systems Laboratory," in 9th AIAA Atmospheric and Space Environments Conference, Benver, 2017.

[21] T. Currie, D. Fuleki and D. C., "Simulation of ice particle melting in the NRCC RATFac Mixed-phase icing tunnel," in SAE technical paper, 2015. 